\title{
Photoinduced electron transfer and unusual environmental effects in
}

\section{Fullerene-Zn-porphyrin-BODIPY triad}

\author{
A. J. Stasyuk, ${ }^{* a}$ O. A. Stasyuk, ${ }^{a}$ M. Solà*a and A. A. Voityuk*a,b
}

a. Institut de Química Computacional and Departament de Química, Universitat de Girona, C/ Maria Aurèlia Capmany 69, 17003 Girona, Spain.

b. Institució Catalana de Recerca i Estudis Avancats (ICREA), 08010 Barcelona, Spain.

\begin{abstract}
.
Molecular arrays containing donor-acceptor sites and antenna molecules are promising candidates for organic photovoltaic devices. Photoinduced electron transfer (PET) in multi-chromophore systems is controlled by a subtle interplay of donor and acceptor properties and solvent effect. In the present study, we explore how PET of fullerene [ $\left.\mathrm{C}_{60}\right]-\mathrm{Zn}$-Porphyrin-BODIPY triad can be modulated by passing from nonpolar to polar media. To this aim we perform computational study of this complex using the DFT/TDDFT method. [ $\mathrm{C}_{60}$ ]-Zn-Porphyrin-BODIPY demonstrates significant contrast between stabilization of CT states in which the BODIPY moiety acts as electron donor forming or electron acceptor. To understand the effect of the environment polarity on the PET processes a detailed analysis of initial and final states involved in the ET is performed. Computed electron transfer rates revealed the dependence of photoinduced charge separation properties on the environment, namely we found that increase in solvent polarity leads to the involvement of an additional deactivation channel, which does not play a role in non-polar solvents.
\end{abstract}

\section{Keywords}

Photoinduced electron transfer; Fullerene; BODIPY; A-D-A triad; Solvent effect.

\section{Introduction.}

Conversion of the sunlight into more accessible forms of energy, such as electrical or chemical ones is a primary challenge for the human race. A lot of attention and efforts were paid to design and preparation of model compounds that mimics natural photosynthetic systems. ${ }^{1-3}$ These systems usually contain an structural unit that absorbs the light (photoantenna) and a reaction center unit, where transfer of electrons in the excited state from the donor to acceptor occurs. ${ }^{4,5}$ Generation of a long-lived chargeseparated (CS) state with high quantum yield and separation of radical ion pairs over long distances to prevent immediate charge recombination processes are extremely important conditions for photosynthetic systems. ${ }^{6-9}$

Many multi-component systems containing different donor and acceptor species have been designed and extensively studied. Among many of potentially suitable chromophores the boron dipyrromethane (BODIPY) and its derivatives, ${ }^{10-13}$ and porphyrinoid families ${ }^{2,14-16}$ appears to be most attractive. These rigid and planar structures have high extinction coefficients, fluorescence quantum yields, and relatively long- 
living singlet excited states. Moreover, their redox potentials and optical properties can be easily tuned by changing the substituents or through the core modification. ${ }^{17,18}$

Among the acceptor units utilized for preparation of photosynthetic systems, fullerenes demonstrate such important properties as low reduction potentials, very strong electron acceptor properties and small reorganization energies. ${ }^{19-27}$ In the last decade, they have got noticeable popularity in chemical and material sciences due to development of their functionalization methods that allowed to overcome solubility issues as well as tune electronic and photophysical properties. ${ }^{28,29}$

The electronic communication between donor and acceptor is a key feature in the design of photosystems. Properties of individual moieties, system energetics, topology and spatial orientation of donor and acceptor subunits have to be also taken into account. ${ }^{30-32}$ Numerous porphyrin-based donoracceptor (D-A) systems have been shown to be excellent models for understanding energy and electron transfer (ET) mechanisms. Various molecular arrays containing multiple D and A sites and antenna molecules, have been prepared and characterized. ${ }^{4,33-37}$ Taking into account that in natural photosynthetic systems the chlorophylls are linked to the protein via axial ligation, much attention was paid to systems where donor and acceptor subunits are axially arranged. ${ }^{38-42}$ Systems where donor and acceptor are located linearly ${ }^{5,34,43-45}$ (in the plane of porphyrin) or V-shaped are also known. ${ }^{46-48}$

In porphyrin-BODIPY arrays, the both fragments complement each other. Porphyrins typically exhibit an intense absorption at $c a .400 \mathrm{~nm}$ and weaker Q-bands in the region of 600-700 nm. BODIPY, at the same time strongly absorb light at 500-600 nm. In this way light-harvesting antennas composed of porphyrinBODIPY fragments undergo quasi-quantitative energy transfer (EnT) between BODIPY and porphyrin units. BODIPY acts as an energy donor, due to absorption of the light at higher energy than the energy of porphyrin Q-band, and transfers singlet state energy to the macrocycle moiety. If the denoted system comprises strong electron acceptor, a charge transfer (CT) from the excited porphyrin to the electron acceptor (fullerene unit, for example) can occurs. ${ }^{49-51}$

Very recently Huaulme et al. reported a synthetic strategy based on oxidative coupling with Fe(III) chloride that allowed to make $\pi$-extended BODIPY-based polycyclic dyes..$^{52}$ Photophysical characterization of series of newly discovered $\alpha$-fused BODIPY revealed that these compounds present an intense absorption (with extinction coefficient up to $2.3 \cdot 10^{5} \mathrm{M}^{-1} \mathrm{~cm}^{-1}$ ) in UV-visible spectral range. Cyclic voltammetry showed that all studied derivatives demonstrated a high electron affinity which is comparable to the electron affinity of $[6,6]$-phenyl- $\mathrm{C}_{61}$-butyric acid methyl ester (PCBM) and similar $\left[\mathrm{C}_{60}\right]$ derivatives.

In a multi-modular systems used in artificial photosynthesis, fullerene $\mathrm{C}_{60}$, porphyrins, and BODIPYs have been extensively utilized. Usually, BODIPY performs the functional role of an energy harvester and is not involved into charge transfer/separation processes. Given the high electron affinity of BODIPY, the [ $\left.\mathrm{C}_{60}\right]-$ Zn-porphyrin(ZnP)-BODIPY complex can be considered a potential acceptor-donor-acceptor (A-D-A) triad $^{53-55}$ with interesting photophysical properties such as the possible existence of different chargeseparated states. Here we report a comprehensive analysis of photoinduced charge separation states in novel Fullerene $\left[\mathrm{C}_{60}\right]$ - ZnP - BODIPY triad using Time-Dependent DFT coupled with conductor-like polarizable continuum model (CPCM) to account for environmental effects. 


\section{Results and discussion}

\section{$\left[\mathrm{C}_{60}\right]-\mathrm{ZnP}-\mathrm{BODIPY}$ triad. Ground state properties.}

Intensive absorption in the NIR rigion and high electron affinity reported for BODIPY, ${ }^{52}$ led us to perform a detailed examination of the electronic properties of such $\alpha$-fused BODIPY. Our analysis revealed intriguing solvation properties. Surprisingly, we found out that anion and cation radicals of such BODIPY derivatives show notably different energies of solvation. For a better understanding of the nature of the observed effect, the BODIPY solvation energies were calculated in several selected solvents differ in polarity ranging from $\varepsilon=1.88$ for $n$-hexane to $\varepsilon=108.94$ for formamide (Table 1 ). Ground state geometries of $\alpha$-fused BODIPY were optimized at BLYP/Def2-SVP level of theory coupled with conductor-like polarizable continuum model (C-PCM) for each solvent. In all cases the structures have been characterized as minima in the potential energy surface.

Table 1. Ground state solvation energies (in eV) computed at C-PCM-CAM-BLYP-D3(BJ)/Def2-SVP//BLYPD3(BJ)/Def2-SVP level of theory for $\alpha$-fused BODIPY taken in neutral, cation radical, and anion radical forms in selected solvents (HEX=n-hexane; TOL=toluene; $D E E=$ diethyl ether; THF=tetrahydrofuran; $\mathrm{DCM}=$ dichloromethane; $\mathrm{DMSO}=$ dimethyl sulfoxide, and $\mathrm{FAM}=$ formamide).

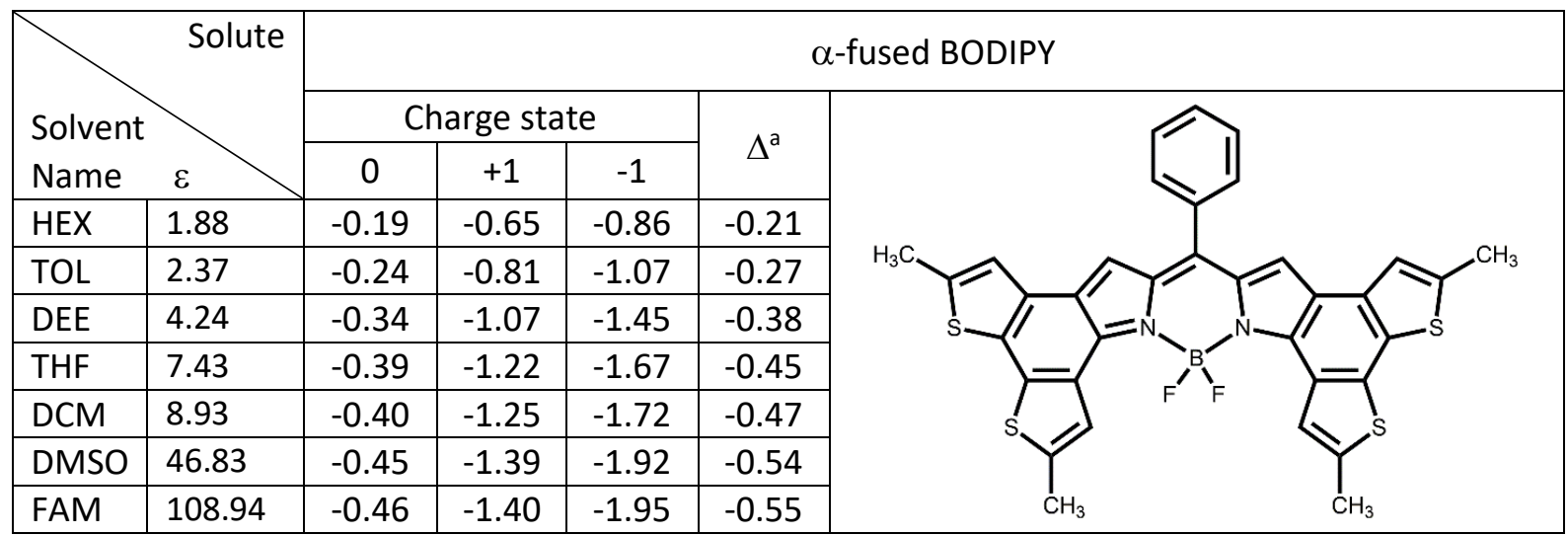

${ }^{a} \Delta$ values show differences in solvation energies between anion radical and cation radical species.

As can be seen from Table 1 the differences in solvation energies between anion radical and cation radical of the BODIPY can reach up to $0.55 \mathrm{eV}$ in polar solvents. The analysis of the charge density distribution computed with iterative Hirshfeld scheme ${ }^{56,57}$ showed that in BODIPY anion radical the charge is significantly more localized compared to cation radical. Usually, the effect of solvation is relatively weak for LE states, while CT states are usually strongly stabilized by the solvent. Taking into account the abovementioned specificity, we hypothesized that the solvent stabilization of CT states can significantly differ depending on the role of the BODIPY fragment. The CT state, where BODIPY moiety acts as an electron donor forming in this way [BODIPY] ${ }^{+}$species, will be stabilized significantly less compared to the CT state, where BODIPY acts as an electron acceptor generating [BODIPY] ${ }^{-}$radical species.

Keeping in mind the high electron affinity of $\alpha$-fused BODIPY as well as its specificity towards solvation, constructed $\left[\mathrm{C}_{60}\right]$-Zn-porphyrin(ZnP)-BODIPY triad with linearly positioned subunits along the central porphyrin core (Figure 1a) has been examined in details. The structure of the constructed triad was optimized at BLYP-D3(BJ)/def2-SVP level. It showes that BODIPY and ZnP fragments are almost co-planar 
(8 degrees). The dihedral angle between $\mathrm{ZnP}$ plane and plane of the pyrrolidine fragment of $\left[\mathrm{C}_{60}\right]$ subunit is about - 60 degree, which indicates the out-of-plane arrangement of the entire fullerene subunit.

To ensure that electronic properties of individual subunits don't change dramatically in the complex. We compare their HOMO and LUMO energies both in the triad and taken individually. In order to eliminate possible changes in electronic properties caused by geometrical changes, the geometries of individually considered fragments have been preserved as in the complex.

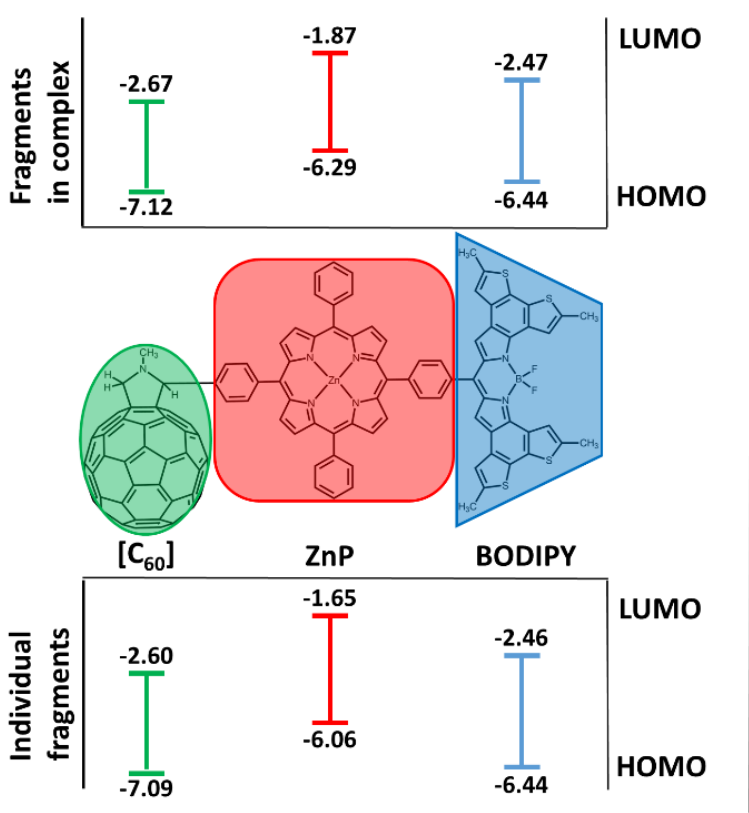

(a)

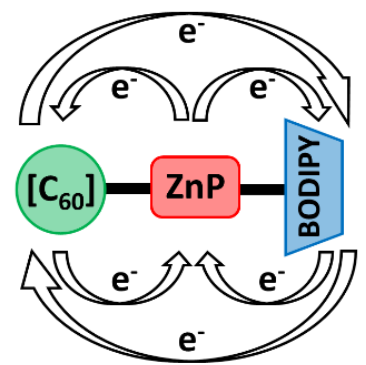

Possible Charge transfer

$\left[\mathrm{C}_{60}\right]-[\mathrm{ZnP}]^{+}-[\text {BODIPY }]^{-} \quad\left[\mathrm{C}_{60}\right]^{-}-[\mathrm{ZnP}]^{+}-[$BODIPY $]$

$\left[\mathrm{C}_{60}\right]^{+}-[\mathrm{ZnP}]-[\mathrm{BODIPY}]^{-} \quad\left[\mathrm{C}_{60}\right]^{-}-[\mathrm{ZnP}]-[\mathrm{BODIPY}]^{+}$

$\left[\mathrm{C}_{60}\right]-[\mathrm{ZnP}]^{-}-[\mathrm{BODIPY}]^{+} \quad\left[\mathrm{C}_{60}\right]^{+}-[\mathrm{ZnP}]^{-}-[\mathrm{BODIPY}]$

(b)

Figure 1. (a) Structure and fragmentation scheme of the $\left[\mathrm{C}_{60}\right]-\mathrm{ZnP}-\mathrm{BODIPY}$ triad and HOMO-LUMO energies for its subunits; (b) Considered electron transfer reactions in the triad.

As can be seen from Figure 1a the orbital energies of $\mathrm{ZnP}$ fragment undergoes significant changes. Both, HOMO and LUMO energies of $\mathrm{ZnP}$ decrease by about $0.22 \mathrm{eV}$. While, orbital energies of [ $\left.\mathrm{C}_{60}\right]$ and BODIPY remain almost unchanged.

The solvation effect on each fragment taken in its neutral, cation radical and anion radical forms has been examined. The difference in solvation energies between anion radical and cation radical for $\left[\mathrm{C}_{60}\right]$ and $\mathrm{ZnP}$ subunits were found to be quite small (about 0.13 and $0.16 \mathrm{eV}$ for $\left[\mathrm{C}_{60}\right]$ and $\mathrm{ZnP}$, correspondingly). The BODIPY solvation energy in complex remains almost unchanged compared to the individual fragment (Table S1, Figure S1, SI).

A designed triad complex represents a quite unique object. From one hand, the fact that electron acceptors ([ $\left.\mathrm{C}_{60}\right]$ and BODIPY) are located at opposite sides with respect to $\mathrm{ZnP}$ central core creates the prerequisites for the formation of entirely different $\mathrm{CT}$ states with localization of the exciton on different and remote from each other fragments. From the other hand, comparable LUMO values for $\left[\mathrm{C}_{60}\right]$ and BODIPY units suggest the possibility of CS between these two moieties. Thus, we can expect up to 6 different $\mathrm{CT}$ types in [ $\mathrm{C}_{60}$ ]-ZnP-BODIPY complex (Figure $1 \mathrm{~b}$ ). Two most expected types of CT is ET between 
$\mathrm{ZnP}$ and $\left[\mathrm{C}_{60}\right]$ or BODIPY, where $\mathrm{ZnP}$ acts as electron donor. Other two types are inverse to previous, in which $\mathrm{ZnP}$ acts as electron acceptor. The last two types correspond to ET between [ $\mathrm{C}_{60}$ ] and BODIPY moieties.

\section{Singlet excited states and environment effect on CT states.}

Analysis of excited states was carried out in terms of excitation delocalization and charge transfer (CT) contributions (Table 2). For this purpose a multi-fragment model has been applied. For the studied complex, several types of excited states can be distinguished: locally excited states (LE), where exciton is mostly localized on a single fragment; excited states corresponded to CT; and mixed states with comparable contributions of LE and CT. We have considered lowest 120 singlet excited states. To assess the effect of the solvent on the excitation energies the equilibrium solvation model with seven different solvents has been applied.

Table 2. Singlet excitation energies $\left(E_{\mathrm{x}}, \mathrm{eV}\right)$, major orbital contributions $(\mathrm{HOMO}(\mathrm{H})-\mathrm{LUMO}(\mathrm{L}))$ and their weights (W), oscillator strength (f), charge separation (CS, e) quantities and the extent of exciton localization (X) of LE states.

\begin{tabular}{|c|c|c|c|c|c|c|c|}
\hline \multirow[b]{2}{*}{ Solvent } & \multicolumn{7}{|c|}{$\left[\mathrm{C}_{60}\right]-Z n P-B O D I P Y$} \\
\hline & HEX & TOL & DEE & THF & DCM & DMSO & FAM \\
\hline & \multicolumn{7}{|c|}{$\mathrm{LE}_{1}$ State (excitation of BODIPY) } \\
\hline$E_{\mathrm{x}}$ & 2.260 & 2.236 & 2.264 & 2.254 & 2.251 & 2.253 & 2.248 \\
\hline $\mathrm{X}$ & 0.93 & 0.92 & 0.92 & 0.93 & 0.93 & 0.92 & 0.93 \\
\hline $\begin{array}{l}\text { Transition } \\
\text { (weight) }\end{array}$ & $\begin{array}{c}H-1-L+1 \\
(0.84)\end{array}$ & $\begin{array}{c}H-2-\mathrm{L} \\
(0.80)\end{array}$ & $\begin{array}{c}H-2-L \\
(0.93)\end{array}$ & $\begin{array}{c}\mathrm{H}-2-\mathrm{L} \\
(0.94)\end{array}$ & $\begin{array}{l}H-2-L \\
(0.94)\end{array}$ & $\begin{array}{c}\mathrm{H}-2-\mathrm{L} \\
(0.94)\end{array}$ & $\begin{array}{c}\mathrm{H}-2-\mathrm{L} \\
(0.94)\end{array}$ \\
\hline$f$ & 1.442 & 1.560 & 1.399 & 1.475 & 1.495 & 1.477 & 1.510 \\
\hline \multirow[t]{2}{*}{ CS } & 0.06 & 0.06 & 0.06 & 0.06 & 0.06 & 0.06 & 0.06 \\
\hline & \multicolumn{7}{|c|}{$\mathrm{LE}_{2}$ State (excitation of $\mathrm{ZnP}$ ) } \\
\hline$E_{\mathrm{x}}$ & 2.295 & 2.289 & 2.285 & 2.278 & 2.276 & 2.266 & 2.263 \\
\hline $\mathrm{X}$ & 0.96 & 0.95 & 0.93 & 0.93 & 0.93 & 0.91 & 0.92 \\
\hline $\begin{array}{l}\text { Transition } \\
\text { (weight) }\end{array}$ & $\begin{array}{c}H-L+4 \\
(0.53)\end{array}$ & $\begin{array}{c}H-L+4 \\
(0.53)\end{array}$ & $\begin{array}{c}H-L+4 \\
(0.52)\end{array}$ & $\begin{array}{c}H-L+4 \\
(0.52)\end{array}$ & $\begin{array}{c}H-L+4 \\
(0.52)\end{array}$ & $\begin{array}{c}H-L+4 \\
(0.51)\end{array}$ & $\begin{array}{c}\mathrm{H}-\mathrm{L}+4 \\
(0.51)\end{array}$ \\
\hline$f$ & 0.115 & 0.125 & 0.140 & 0.142 & 0.145 & 0.160 & 0.157 \\
\hline \multirow[t]{2}{*}{ CS } & 0.03 & 0.03 & 0.04 & 0.05 & 0.05 & 0.06 & 0.07 \\
\hline & \multicolumn{7}{|c|}{$\mathrm{CT}_{1}$ State $(\mathrm{ZnP} \rightarrow \mathrm{BODIPY})$} \\
\hline$E_{\mathrm{x}}$ & 2.212 & 2.040 & 1.719 & 1.540 & 1.480 & 1.225 & 1.191 \\
\hline $\begin{array}{l}\text { Transition } \\
\text { (weight) }\end{array}$ & $\begin{array}{c}\mathrm{H}-\mathrm{L}+1 \\
(0.85)\end{array}$ & $\begin{array}{l}H-L \\
(0.84)\end{array}$ & $\begin{array}{l}H-L \\
(0.84)\end{array}$ & $\begin{array}{c}H-1-L \\
(0.95)\end{array}$ & $\begin{array}{l}\mathrm{H}-1-\mathrm{L} \\
(0.95)\end{array}$ & $\begin{array}{c}H-1-L \\
(0.96)\end{array}$ & $\begin{array}{c}H-1-L \\
(0.96)\end{array}$ \\
\hline$f$ & 0.319 & 0.318 & 0.266 & 0.031 & 0.032 & 0.029 & 0.03 \\
\hline \multirow[t]{2}{*}{ CS } & 0.82 & 0.82 & 0.81 & 0.89 & 0.89 & 0.89 & 0.89 \\
\hline & \multicolumn{7}{|c|}{$\mathrm{CT}_{2}$ State $\left(\mathrm{ZnP} \rightarrow\left[\mathrm{C}_{60}\right]\right)$} \\
\hline$E_{\mathrm{x}}$ & 2.426 & 2.322 & 2.219 & 2.056 & 1.994 & 1.762 & 1.734 \\
\hline $\begin{array}{l}\text { Transition } \\
\text { (weight) }\end{array}$ & $\begin{array}{l}H-L \\
(0.91)\end{array}$ & $\begin{array}{c}H-L+1 \\
(0.90)\end{array}$ & $\begin{array}{c}H-L+2 \\
(0.92)\end{array}$ & $\begin{array}{c}H-L+2 \\
(0.93)\end{array}$ & $\begin{array}{c}\mathrm{H}-1-\mathrm{L}+1 \\
(0.88)\end{array}$ & $\begin{array}{c}H-L+1 \\
(0.92)\end{array}$ & $\begin{array}{c}H-L+1 \\
(0.92)\end{array}$ \\
\hline$f$ & 0.004 & 0.006 & 0.020 & 0.022 & 0.002 & 0.003 & 0.003 \\
\hline \multirow[t]{2}{*}{$\mathrm{CS}$} & 0.93 & 0.93 & 0.95 & 0.96 & 0.90 & 0.94 & 0.94 \\
\hline & \multicolumn{7}{|c|}{$\mathrm{CT}_{3}$ State (BODIPY $\left.\rightarrow\left[\mathrm{C}_{60}\right]\right)$} \\
\hline
\end{tabular}




\begin{tabular}{|c|c|c|c|c|c|c|c|}
\hline$E_{\mathrm{x}}$ & 2.929 & 2.788 & 2.524 & 2.358 & 2.323 & 2.154 & 2.130 \\
\hline $\begin{array}{l}\text { Transition } \\
\text { (weight) }\end{array}$ & $\begin{array}{c}\mathrm{H}-1-\mathrm{L} \\
(0.87)\end{array}$ & $\begin{array}{c}\mathrm{H}-2-\mathrm{L}+1 \\
(0.86)\end{array}$ & $\begin{array}{c}\mathrm{H}-2-\mathrm{L}+1 \\
(0.99)\end{array}$ & $\begin{array}{c}\mathrm{H}-2-\mathrm{L}+1 \\
(0.99)\end{array}$ & $\begin{array}{c}H-2-L+1 \\
(0.99)\end{array}$ & $\begin{array}{c}\mathrm{H}-2-\mathrm{L}+1 \\
(1.00)\end{array}$ & $\begin{array}{c}\mathrm{H}-2-\mathrm{L}+1 \\
(1.00)\end{array}$ \\
\hline$f$ & 0.008 & $<0.001$ & $<0.001$ & $<0.001$ & $<0.001$ & $<0.001$ & $<0.001$ \\
\hline CS & 0.99 & 1.00 & 1.00 & 1.00 & 1.00 & 1.00 & 1.00 \\
\hline & \multicolumn{7}{|c|}{$\mathrm{CT}_{4}$ State $\left(\left[\mathrm{C}_{60}\right] \rightarrow\right.$ BODIPY $)$} \\
\hline$E_{\mathrm{x}}$ & 3.253 & 2.926 & 2.341 & 2.142 & 1.965 & 1.773 & 1.600 \\
\hline $\begin{array}{l}\text { Transition } \\
\text { (weight) }\end{array}$ & $\begin{array}{c}H-5-L+1 \\
(0.89)\end{array}$ & $\begin{array}{c}H-5-\mathrm{L} \\
(0.92)\end{array}$ & $\begin{array}{c}H-5-\mathrm{L} \\
(0.95)\end{array}$ & $\begin{array}{c}H-7-\mathrm{L} \\
(0.97)\end{array}$ & $\begin{array}{c}H-5-\mathrm{L} \\
(0.94)\end{array}$ & $\begin{array}{c}\mathrm{H}-4-\mathrm{L} \\
(0.92)\end{array}$ & $\begin{array}{c}\mathrm{H}-4-\mathrm{L} \\
(0.93)\end{array}$ \\
\hline$f$ & 0.001 & 0.001 & 0.002 & $<0.001$ & 0.004 & 0.008 & 0.006 \\
\hline \multirow[t]{2}{*}{ CS } & 0.96 & 0.98 & 0.98 & 0.99 & 0.96 & 0.94 & 0.95 \\
\hline & \multicolumn{7}{|c|}{$\mathrm{CT}_{5}$ State (BODIPY $\rightarrow \mathrm{ZnP}$ ) } \\
\hline$E_{\mathrm{x}}$ & 3.340 & 3.236 & 2.991 & 2.838 & 2.805 & 2.706 & 2.628 \\
\hline $\begin{array}{l}\text { Transition } \\
\text { (weight) }\end{array}$ & $\begin{array}{c}\mathrm{H}-1-\mathrm{L}+4 \\
(0.82)\end{array}$ & $\begin{array}{c}\mathrm{H}-2-\mathrm{L}+4 \\
(0.82)\end{array}$ & $\begin{array}{c}\mathrm{H}-2-\mathrm{L}+5 \\
(0.98)\end{array}$ & $\begin{array}{c}\mathrm{H}-2-\mathrm{L}+5 \\
(0.98)\end{array}$ & $\begin{array}{c}H-2-L+5 \\
(0.98)\end{array}$ & $\begin{array}{c}\mathrm{H}-2-\mathrm{L}+5 \\
(0.97)\end{array}$ & $\begin{array}{c}\mathrm{H}-2-\mathrm{L}+5 \\
(0.98)\end{array}$ \\
\hline$f$ & 0.021 & 0.018 & $<0.001$ & $<0.001$ & $<0.001$ & $<0.001$ & $<0.001$ \\
\hline \multirow[t]{2}{*}{ CS } & 0.98 & 0.98 & 0.99 & 0.99 & 0.99 & 0.98 & 0.99 \\
\hline & \multicolumn{7}{|c|}{$\mathrm{CT}_{6}$ State $\left(\left[\mathrm{C}_{60}\right] \rightarrow \mathrm{ZnP}\right)$} \\
\hline$E_{\mathrm{x}}$ & 3.785 & 3.610 & 3.459 & 3.312 & 3.180 & 2.838 & 2.833 \\
\hline $\begin{array}{l}\text { Transition } \\
\text { (weight) }\end{array}$ & $\begin{array}{c}H-5-L+4 \\
(0.88)\end{array}$ & $\begin{array}{c}H-5-L+4 \\
(0.88)\end{array}$ & $\begin{array}{c}H-5-L+5 \\
(0.80)\end{array}$ & $\begin{array}{c}H-8-\mathrm{L} \\
(0.35)\end{array}$ & $\begin{array}{c}H-5-L+5 \\
(0.81)\end{array}$ & $\begin{array}{c}\mathrm{H}-4-\mathrm{L}+5 \\
(0.83)\end{array}$ & $\begin{array}{c}H-4-L+5 \\
(0.77)\end{array}$ \\
\hline$f$ & 0.004 & 0.004 & 0.009 & 0.015 & 0.003 & 0.005 & 0.003 \\
\hline $\mathrm{CS}$ & 0.94 & 0.93 & 0.84 & 0.77 & 0.86 & 0.93 & 0.93 \\
\hline
\end{tabular}

Two lowest $L_{1}$ and $L_{2}$ states correspond to the excited states with exciton localization on BODIPY and $\mathrm{ZnP}$ fragments, respectively. $\mathrm{LE}_{1}$ state associated with BODIPY fragment is characterized by significant probability of the light absorption ( $f$ varies from 1.40 to 1.56 depending on solvent). For the $\mathrm{LE}_{2}$ state associated with ZnP subunit the corresponding probability is one order of magnitude less and could be identified as porphyrin Q-band. Both LE states are very close energetically to each other.

It is well known that solvation may significantly influence both ground and excited states. In the ground state, the dipole moment varies in the range from 7.82D in hexane to 9.66D in formamide solvent. Despite the fact that dipole moment changes by only $20 \%$ when going from non-polar to highly polar solvents, the differences in the solvation energies are tremendous and lie in the range from -0.275 ( $n$-hexane) to -0.733 (formamide) eV. $\mathrm{LE}_{1}$ and $\mathrm{LE}_{2}$ states demonstrate smallest changes in the dipole moments compared to the ground state, which is reflected in the minimal changes in the solvation energies. As can be seen from Table 2, in a wide range of solvent polarity (from $\varepsilon=1.88$ for $n$-hexane to $\varepsilon=108.94$ for formamide) the relative energies of LE states vary by less than $0.05 \mathrm{eV}$.

Within the considered 120 excited states all expected types of charge transfer states (Figure 1b) have been identified. For studied [ $\left.\mathrm{C}_{60}\right]$-ZnP-BODIPY triad, the lowest lying excited states, regardless the solvent polarity, correspond to the ET from porphyrin unit to BODIPY fragment. In non-polar solvents (hexane and toluene) this is the only type of CT that is thermodynamically favorable (Figure 2). 


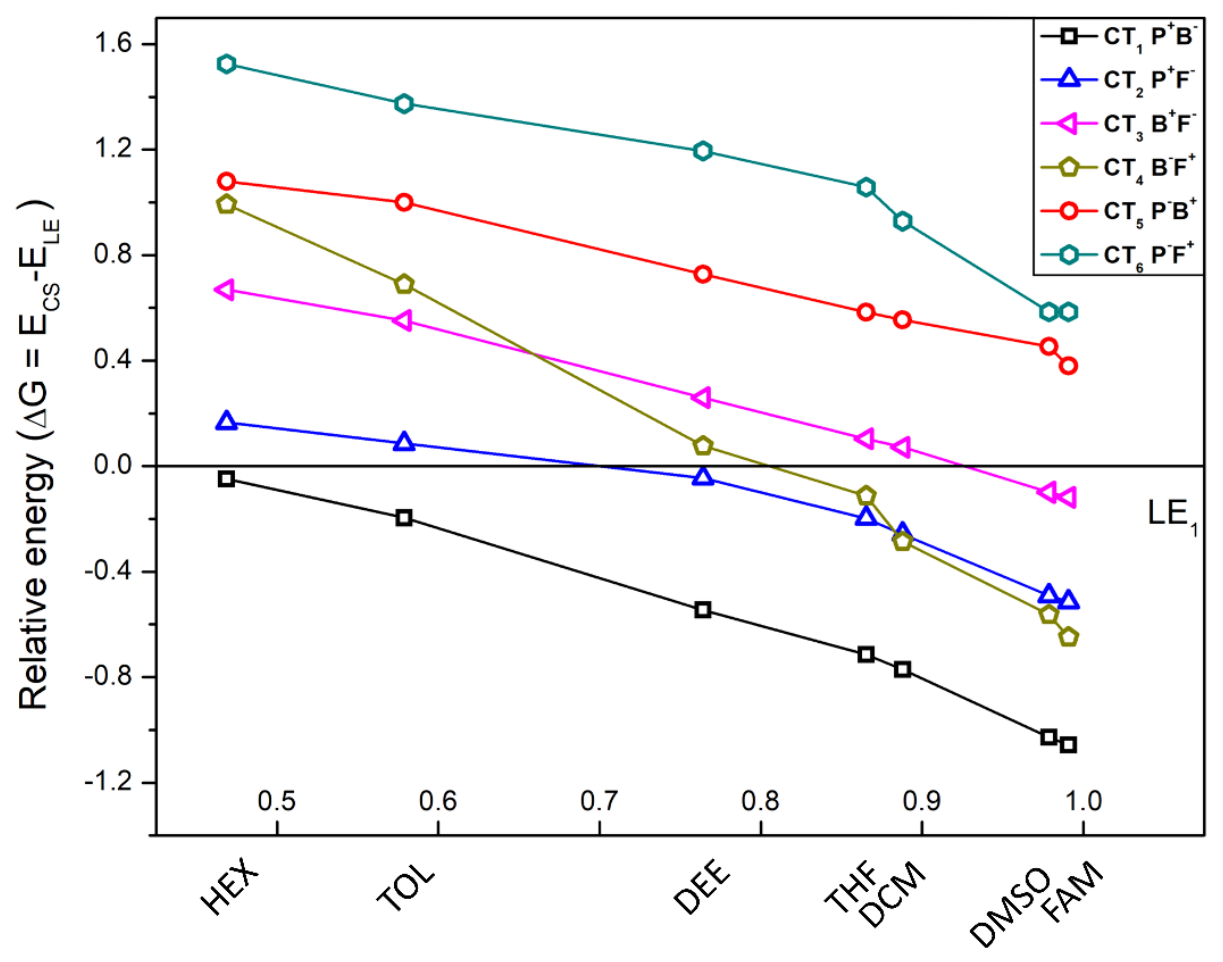

Effective scaling factor, $f(\varepsilon)=\frac{\varepsilon-1}{\varepsilon}$

Figure 2. The Gibbs energy change of charge separation processes $\left(C T_{1}-C T_{6}\right)$ in different solvents.

The solvent stabilization effect increases with solvent polarity. In diethyl ether solution, the ET from $\mathrm{ZnP}$ to $\left[\mathrm{C}_{60}\right]$ becomes also lower in energy than lowest LE state. Moving to highly polar environment, such as DMSO and formamide, we observe a thermodynamic favorable driving force for already four types of CT state. CT states where $\mathrm{ZnP}$ unit acts as electron acceptor, that is ET occurs from BODIPY or [ $\mathrm{C}_{60}$ ] subunits to $\mathrm{ZnP}$, are high in energy and never appear lower than lowest LE state (Table 2, Figure 2).

An interesting feature has been found in solvation of $\mathrm{CT}_{3}$ and $\mathrm{CT}_{4}$ states resulted from the $\mathrm{ET}$ between BODIPY and $\left[\mathrm{C}_{60}\right]$. The $\mathrm{CT}_{4}$ state, where electron density transfers from [ $\mathrm{C}_{60}$ ] to BODIPY, demonstrates significantly stronger stabilization by solvent compared to the $\mathrm{CT}_{3}$ state characterized by ET from BODIPY to $\left[\mathrm{C}_{60}\right]$. In non-polar solvents, $\mathrm{CT}_{3}$ state is energetically lower than $\mathrm{CT}_{4}$. However, the situation is reversed with increase in solvent polarity. The reason for such behavior is the previously noted specific solvent effect on BODIPY anion- and cation-radicals. Anion-radical stabilizes much stronger than the cation-radical (Table 1), which in turn is responsible for the observed different behavior. Relative energy for corresponding to the direct and reversed CT processes and their differential charts as function of polarity of the media are shown at Figure S2. Visualization of HOMO to LUMO transitions for the LE and CT states are shown in Figure S3, SI. Comparison of absorption spectra for [ $\left.\mathrm{C}_{60}\right]$-ZnP-BODIPY triad clearly demonstrates the solvation effect discussed above. As can be seen the intensive absorption band for BODIPY (around $550 \mathrm{~nm}$ ) and both Soret and Q bands for ZnP (around 350 and $545 \mathrm{~nm}$, respectively) remain almost unchanged. At the same time, bands corresponded to CT states showed a notable red shift. In DMSO solution, the absorption band corresponded to $\mathrm{CT}_{1}$ state can be found at wavelengths greater than $1000 \mathrm{~nm}$ (Figure 3). 


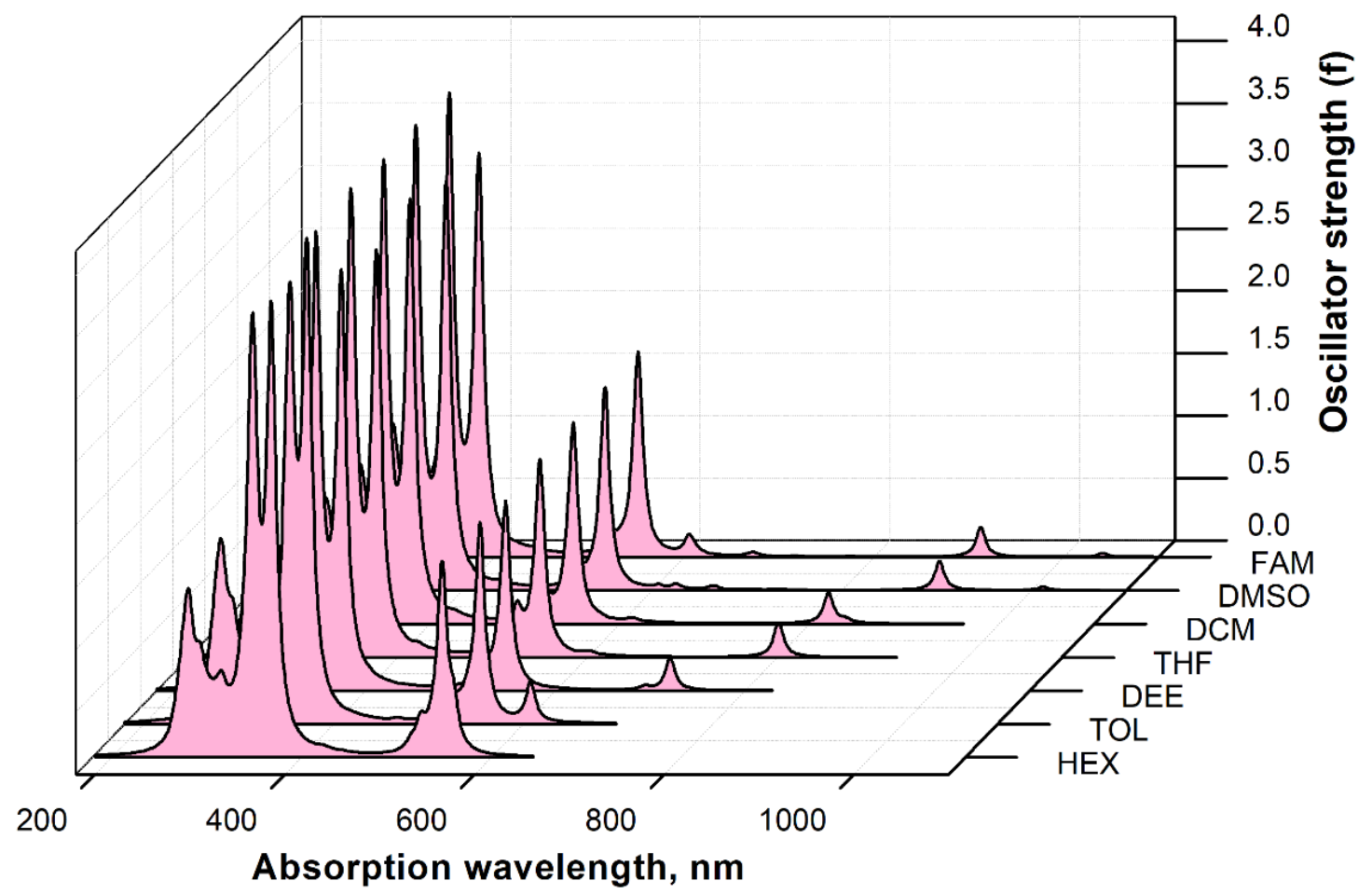

Figure 3. Simulated absorption spectra of $\left[\mathrm{C}_{60}\right]-\mathrm{ZnP}-\mathrm{BODIPY}$ triad in different solvents.

Despite the fact that all 6 types of CT states in the complex were detected within less than 2 eV energy gap, their different stabilization by solvents provides a simple way to manipulate their relative stability by changing the polarity of the solvent.

\section{Electron transfer rates.}

Absorption of the light by the studied complex leads to generation of the excited states, which extremely fast interconvert to the lowest lying excited state. Most of CT states are characterized by very low oscillator strength and probability of their direct population is very low. However, generation of CT states is possible through the interaction of lowest LE state with particular CT state. The CT states populated in such manner can finally undergo charge recombination reaction to recover the ground state. In our case, both $\mathrm{ZnP}$ and BODIPY fragments exhibit highly absorptive bands. When the exciton is localized on BODIPY unit ( $\left.\mathrm{LE}_{1}\right)$, generation of $\mathrm{CT}_{1}, \mathrm{CT}_{3}, \mathrm{CT}_{4}$, and $\mathrm{CT}_{5}$ states is possible, whereas when the exciton is localized on $\mathrm{ZnP}$ unit $\left(\mathrm{LE}_{2}\right), \mathrm{CT}_{1}, \mathrm{CT}_{2}, \mathrm{CT}_{5}$, and $\mathrm{CT}_{6}$ states can be generated. Considering the fact that $\mathrm{LE}_{1}$ and $\mathrm{LE}_{2}$ are very close energetically to each other, the possibility of direct and reverse $\left(L_{1} \leftrightarrow \mathrm{LE}_{2}\right)$ exciton transfer must be taken into account.

We used the Marcus theory to compute the rate for charge and exciton transport. ${ }^{58}$ The rate of electron/exciton transfer is controlled by three parameters - the exciton/electronic coupling $V_{i j}$ between the initial and final states, the reorganization energy $\lambda$, and the Gibbs energy of the reaction $\Delta G_{0}$. The reorganization energy is usually divided into two parts, $\lambda=\lambda_{i}+\lambda_{s}$, the internal energy required to rearrange all the nuclei of the system due to $\mathrm{CT}$ reaction and solvent terms due to changes in solvent polarization, respectively. Taking into account that donor and acceptor parts are involved in the CT processes, a two-fragment approach has been used. Internal reorganization energy was calculated based 
on the energy differences of the anion- and the cation- radicals taken in their equilibrium geometries as well as at geometries of the neutral species. Solvent reorganization energy was accounted for entire excited state of interest using a COSMO-like polarizable continuum model (CPCM) in the monopole approximation..$^{59}$ For detailed description of the internal and solvent reorganization energies calculations see supporting information. The calculated values of exciton/electronic couplings between $L_{1}$ and $L_{2}$ and LE and CT states, as well as CT and GS state, reorganization energies, Gibbs energies of the reactions in various solvents are listed in Tables S2-S4, SI.

Firstly, we consider the case then $\mathrm{LE}_{1}$ and $\mathrm{LE}_{2}$ states are populated independently (Figure 4).
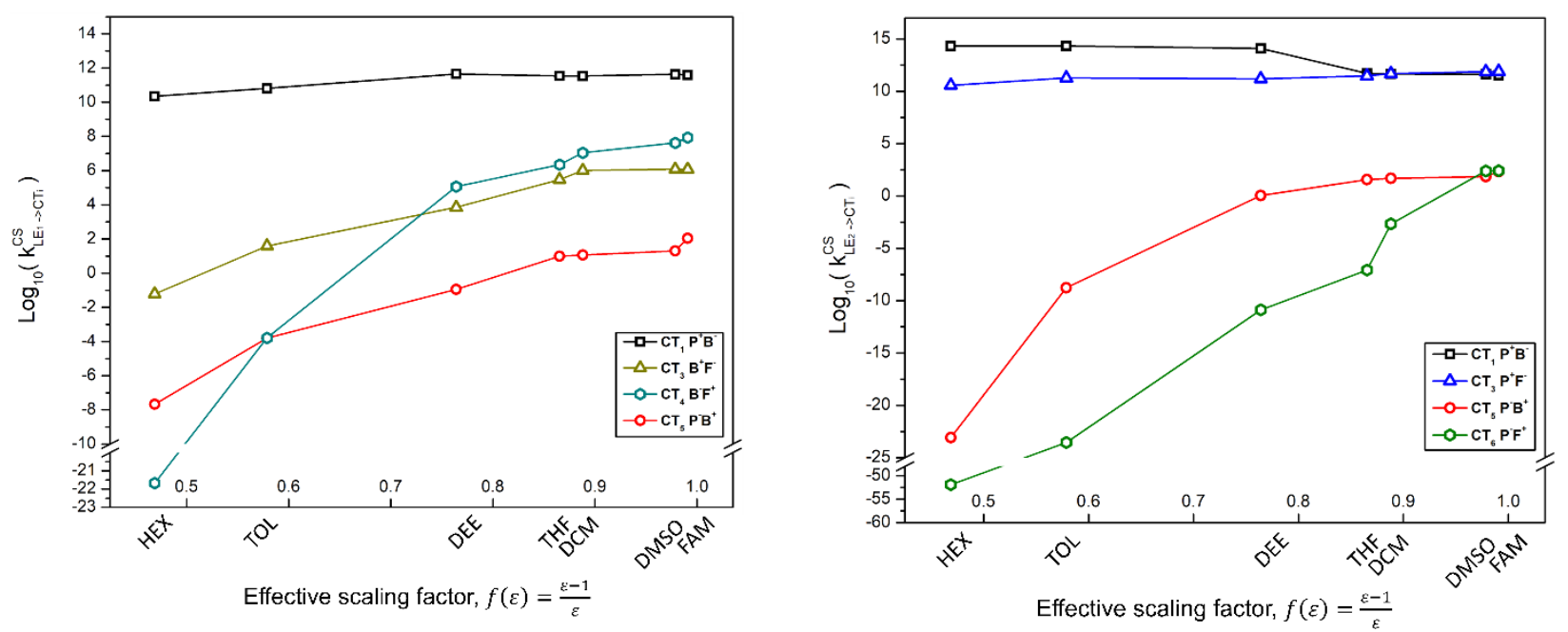

(a)

Figure 4. Computed photoinduced charge separation rates from $\mathrm{LE}_{1}$ (left panel) and $\mathrm{LE}_{2}$ (right panel) states.

As seen in Figure $4 a$, the generation of $\mathrm{CT}_{1}$ state is the fastest process when it is generates from $\mathrm{LE}_{1} . \mathrm{k}^{\mathrm{CS}}$ varies from 22 to $388 \mathrm{~ns}^{-1}$ depending on the solvent. No other processes on the same time scale were observed. The rate of generation of $\mathrm{CT}_{3}$ and $\mathrm{CT}_{4}$ states races significantly with solvent polarity, but it still about 3 order of magnitude slower compared to the rate of $\mathrm{CT}_{1}$. This picture changes dramatically when we consider the formation of $\mathrm{CT}$ states from $\mathrm{LE}_{2}$. Thus, in [ $\left.\mathrm{C}_{60}\right]$-ZnP-BODIPY we can distinguish two fast processes - generation of $\mathrm{CT}_{1}$ (ET ZnP $\rightarrow$ BODIPY) and $\mathrm{CT}_{3}$ (ET ZnP $\rightarrow\left[\mathrm{C}_{60}\right]$ ) states. In non-polar solvents, the rate $L E_{2} \rightarrow C T_{1}$ is about 3 to 4 order of magnitude faster than $C_{3}$. This rate drops notable by increasing solvent polarity and in $\operatorname{DCM}(\varepsilon=8.93)$ it becomes comparable with the rate of $\mathrm{CT}_{3}$ rate (Figure $4 \mathrm{~b}$ ).

Note that deactivation of LE1 and LE2 states can proceed through with two competing reactions - (a) electron transfer (with formation of CT states) and the energy transfer between BODIPY and ZnP.

Let us consider now the case then, in real conditions (photoexcitation with light characterized by some frequency/wavelength variation) both $\mathrm{LE}_{1}$ and $\mathrm{LE}_{2}$ states can be populated at the same time due to proximity of energy levels. A possible exciton transfer, i.e. the energy transfer between BODIPY and ZnP units, must also be considered. In this way, the deactivation of $\mathrm{LE}_{1}$ states has been considered as a process with two competing reactions - electron transfer (to generate CT state) and exciton transfer between $\mathrm{LE}_{1}$ and $\mathrm{LE}_{2}$. If the $\mathrm{CT}$ state can be generated from different LE states the total rate of its formation is sum of the individual rates. The data for exciton transfer between $L E_{1}$ and $L E_{2}$, and charge separation rates in various solvents are listed in Table S5, SI. 
Comparison of the $\left[\mathrm{C}_{60}\right]-\mathrm{ZnP}-\mathrm{BODIPY}$ system behavior towards photoinduced electron transfer in different solvents (toluene $\varepsilon=2.37$ and DMSO $\varepsilon=46.83$ ) is given in Figure 5 .

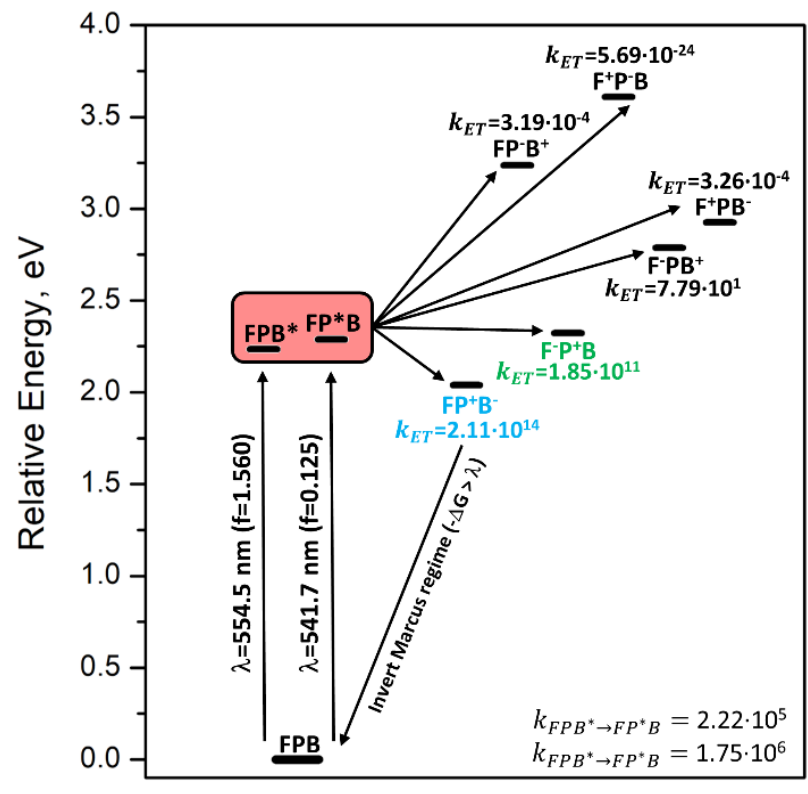

Toluene $(\varepsilon=2.37)$

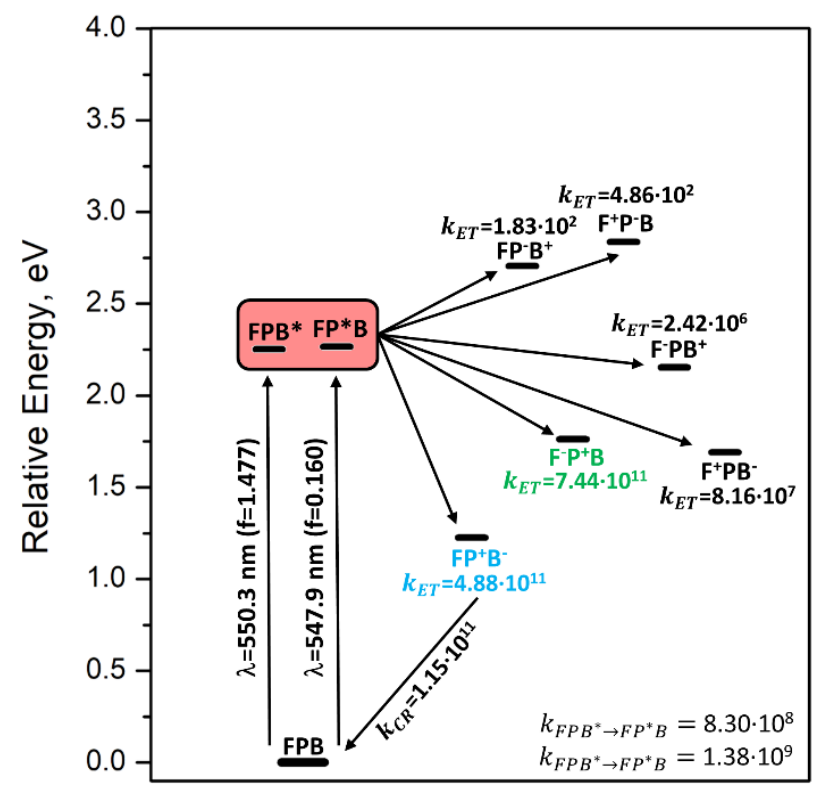

Dimethyl sulfoxide $(\varepsilon=46.83)$

Figure 5. Photoinduced electron transfer rate constant computed for supramolecular $\left[\mathrm{C}_{60}\right]-\mathrm{ZnP}-\mathrm{BODIPY}$ triad system in toluene (left) and dimethyl sulfoxide (right) media.

Our calculations predict that the studied [ $\left.\mathrm{C}_{60}\right]-\mathrm{ZnP}-\mathrm{BODIPY}$ triad exhibits photoinduced charge separation properties that strongly depend on solvent polarity. In non-polar solvents, deactivation of the excited state occurs mainly through the formation of single charge separated state corresponded to the ET from central ZnP core to BODIPY fragment. However, increase in solvent polarity leads to importance of second deactivation channel, i.e. ET from $\mathrm{ZnP}$ core to $\left[\mathrm{C}_{60}\right]$ unit. Thus, photoinduced charge separation in the studied system occurs in nanosecond scale and can be significantly modulated by changing the environment.

\section{Conclusions}

The structure and excited state properties of the $\left[\mathrm{C}_{60}\right]-\mathrm{ZnP}-\mathrm{BODIPY}$ triad have been studied by DFT/TDDFT calculations. Due to different solvation of the BODIPY anion- and cation-radicals the multi-chromophore complex demonstrates remarkably different stabilization of CT states where BODIPY acts as electron donor or electron acceptor. A striking example of such behavior is dramatic relative energy dependence of $\mathrm{CT}_{3}\left(\left[\mathrm{C}_{60}\right]^{-}-\mathrm{ZnP}-\mathrm{BODIPY}\right)$ and $\left.\mathrm{CT}_{4}\left(\left[\mathrm{C}_{60}\right]^{+}-\mathrm{ZnP}-\mathrm{BODIPY}\right)^{-}\right)$states on the solvent polarity. All six possible charge-transfer states of different nature have been identified. Analysis of the calculated ET rates revealed the dependence of photoinduced charge separation properties on environment, namely we found that increase in solvent polarity leads to the involvement of additional deactivation channel, which does not play a noticeable role in non-polar solvents. 


\section{Methods}

General. Geometry optimizations were performed employing the DFT BLYP ${ }^{60,61}$ exchange-correlation functional with Ahlrichs' Def2-SVP basis set. ${ }^{62,63}$ and using the resolution of identity approximation (RI, alternatively termed density fitting ${ }^{64}$ implemented in the TURBOMOLE 7.0 program. ${ }^{65}$ The restricted formalism was used for closed-shell systems and the unrestricted approach was followed for the openshell species. Electronic structures calculations and vertical excitation energies were calculated using TDA formalism ${ }^{66}$ with the range-separated functional from Handy and coworkers' CAM-B3LYP ${ }^{67}$ using Gaussian 16 (rev. A03) ${ }^{68}$ and Ahlrichs' Def2-SVP basis set. ${ }^{62,63}$ The empirical dispersion D3 correction with BeckeJohnson damping, ${ }^{69,70}$ was employed. TDA is a popular method in computational chemistry because it is formally simpler than the full Casida formalism and thus can save computational time. It is also worthwhile to note that for a long-range CT state in the TDDFT the $\mathbf{B}$ matrix vanishes that is equivalent to applying the Tamm-Dancoff approximation. Thus, TDDFT and TDDFT/TDA yield identical results for the excitation energies of long-range CT states. ${ }^{71-73}$ Frontier molecular orbitals as well as molecular structures were visualized using an Chemcraft $1.8 .^{74}$

Analysis of excited states. The quantitative analysis of exciton delocalization and charge transfer in the donor-acceptor complexes was carried out using a tool suggested recently by Plasser et al. ${ }^{75,76}$

A key quantity is the parameter $\Omega$ :

$$
\begin{aligned}
& \Omega(\mathrm{A}, \mathrm{B})=\frac{1}{2} \sum_{\alpha \in \mathrm{A}, \beta \in \mathrm{B}}\left[\left(\mathrm{SP}^{0 \mathrm{i}}\right)_{\alpha \beta}\left(\mathrm{P}^{0 \mathrm{i}} \mathrm{S}\right)_{\alpha \beta}+\mathrm{P}_{\alpha \beta}^{0 \mathrm{i}}\left(\mathrm{SP}^{0 \mathrm{i}} \mathrm{S}\right)_{\alpha \beta}\right] \\
& \mathrm{X}\left(\mathrm{F}_{\mathrm{i}}\right)=\sum_{\mathrm{A} \in \mathrm{F}_{\mathrm{i}}} \Omega(\mathrm{A}, \mathrm{A}) \\
& \Delta \mathrm{q}\left(\mathrm{CT}^{\mathrm{F}_{\mathrm{i}} \rightarrow \mathrm{F}_{\mathrm{j}}}\right)=\sum_{\mathrm{A} \in \mathrm{F}_{\mathrm{i}}, \mathrm{B} \in \mathrm{F}_{\mathrm{j}}} \Omega(\mathrm{A}, \mathrm{B})+\Omega(\mathrm{B}, \mathrm{A}) \\
& \Delta \mathrm{q}\left(\mathrm{CS}^{\mathrm{F}_{\mathrm{i}} \rightarrow \mathrm{F}_{\mathrm{j}}}\right)=\sum_{\mathrm{A} \in \mathrm{F}_{\mathrm{i}}, \mathrm{B} \in \mathrm{F}_{\mathrm{j}}} \Omega(\mathrm{A}, \mathrm{B})-\Omega(\mathrm{B}, \mathrm{A})
\end{aligned}
$$

where $A$ and $B$ are atoms, $F_{i}$ and $F_{j}$ are fragments, $\alpha$ and $\beta$ are atomic orbitals, $\mathbf{P}^{0 i}$ is the transition density matrix for the $\psi_{0} \rightarrow \psi_{i}$ excitation, and $S$ is the overlap matrix. $X\left(F_{i}\right)$ is the extent of exciton localization on the fragment $\mathrm{F}_{\mathrm{i} . \Delta} \Delta \mathrm{q}\left(C T^{F_{i} \rightarrow F_{j}}\right)$ is the total amount of the electron density transferred between fragments $F_{i}$ and $F_{j}$ in the $\psi_{0} \rightarrow \psi_{\mathrm{i}}$ excitation. $\left.\Delta \mathrm{q}\left(C S^{F_{i} \rightarrow F_{j}}\right)\right)$ is a measure of the charge separation between fragments $F_{i}$ and $F_{j}$. Note that in the situation when when charge transfer $\left(F_{i} \rightarrow F_{j}\right)$ is equal to the back transfer $\left(F_{j} \rightarrow F_{i}\right)$ there is no charge separation between the fragments, $\mathrm{CS}^{\mathrm{F}_{\mathrm{i}} \rightarrow \mathrm{F}_{\mathrm{j}}}$ is equal to zero.

Solvent Effects. The equilibrium solvation energy $E_{S}^{e q}$ in a medium with dielectric constant $\varepsilon$ was estimated using a COSMO-like polarizable continuum model (CPCM) in the monopole approximation. ${ }^{59}$ 


$$
\mathrm{E}_{\mathrm{S}}^{\mathrm{eq}}(\mathrm{Q}, \varepsilon)=-\frac{1}{2} f(\varepsilon) \mathrm{Q}^{+} \mathrm{DQ}
$$

where $f(\varepsilon)$ is the dielectric scaling factor, $f(\varepsilon)=\frac{\varepsilon-1}{\varepsilon}, \mathbf{Q}$ is the vector of $n$ atomic charges in the molecular system, and $\mathbf{D}$ is the $n \times n$ symmetric matrix determined by the shape of the boundary surface between solute and solvent; $\mathbf{D}=\mathbf{B}^{+} \mathbf{A}^{-1} \mathbf{B}$, where the $m \times m$ matrix $\mathbf{A}$ describes electrostatic interaction between $m$ surface charges and the $m \times n \mathbf{B}$ matrix describes the interaction of the surface charges with $n$ atomic charges of the solute. Atomic charges in the excited state $\psi_{\mathrm{i}}$, were calculated using Eqs. 1-4.

\section{Electron transfer rates.}

The rate of the nonadiabatic $\mathrm{ET}, k_{\mathrm{ET}}$, can be expressed in terms of the electronic coupling squared, $V^{2}$, and the Franck-Condon Weighted Density of states (FCWD):

$$
k_{E T}=\frac{2 \pi}{\hbar^{2}} V^{2}(F C W D)
$$

that accounts for the overlap of vibrational states of donor and acceptor and can be approximately estimated using the classical Marcus equation: ${ }^{58}$

$$
(F C W D)=(4 \pi \lambda k T)^{-1 / 2} \exp \left[-\left(\Delta G^{0}+\lambda\right)^{2} / 4 \lambda k T\right]
$$

where $\lambda$ is the reorganization energy and $\Delta G^{0}$ is the standard Gibbs energy change of the process. The fragment charge difference $(F C D)^{77,78}$ method was employed to calculate the electronic couplings in this work.

\section{Conflicts of interest}

There are no conflicts to declare.

\section{Acknowledgments}

We are grateful for financial support from the Spanish MINECO (Network CTQ2016-81911-REDT and projects CTQ2017-85341-P and CTQ2015-69363-P), the Catalan DIUE (2017SGR39, XRQTC, and ICREA Academia 2014 Award to M.S.), and the FEDER fund (UNGI10-4E-801). Juan de la Cierva formación contracts (FJCl-2016-29448 to A.J.S. and FJCI-2017-32757 to O.A.S.) are acknowledged. 


\section{References}

1. M. R. Wasielewski, Chem. Rev., 1992, 92, 435-461.

2. G. Bottari, O. Trukhina, M. Ince and T. Torres, Coord. Chem. Rev., 2012, 256, 2453-2477.

3. R. L. House, N. Y. M. Iha, R. L. Coppo, L. Alibabaei, B. D. Sherman, P. Kang, M. K. Brennaman, P. G. Hoertz and T. J. Meyer, J. Photochem. Photobiol., C, 2015, 25, 32-45.

4. F. D'Souza and O. Ito, Coord. Chem. Rev., 2005, 249, 1410-1422.

5. D. M. Guldi, Chem. Soc. Rev., 2002, 31, 22-36.

6. S. Fukuzumi, T. Honda, K. Ohkubo and T. Kojima, Dalton Trans., 2009, 0, 3880-3889.

7. S. Fukuzumi, K. Ohkubo and T. Suenobu, Acc. Chem. Res., 2014, 47, 1455-1464.

8. $\quad$ F. D'Souza and O. Ito, Chem. Soc. Rev., 2012, 41, 86-96.

9. F. D'Souza, R. Chitta, K. Ohkubo, M. Tasior, N. K. Subbaiyan, M. E. Zandler, M. K. Rogacki, D. T. Gryko and S. Fukuzumi, J. Am. Chem. Soc., 2008, 130, 14263-14272.

10. Y. Rio, W. Seitz, A. Gouloumis, P. Vázquez, J. L. Sessler, D. M. Guldi and T. Torres, Chem. - Eur. J., 2010, 16, 1929-1940.

11. N. J. L. K. Davis, R. W. MacQueen, S. T. E. Jones, C. Orofino-Pena, D. Cortizo-Lacalle, R. G. D. Taylor, D. Credgington, P. J. Skabara and N. C. Greenham, J. Mater. Chem. C, 2017, 5, 1952-1962.

12. L. Li, J. Han, B. Nguyen and K. Burgess, J. Org. Chem., 2008, 73, 1963-1970.

13. V. Leen, D. Miscoria, S. Yin, A. Filarowski, J. Molisho Ngongo, M. Van der Auweraer, N. Boens and W. Dehaen, J. Org. Chem., 2011, 76, 8168-8176.

14. G. Rotas, G. Charalambidis, L. Glätzl, D. T. Gryko, A. Kahnt, A. G. Coutsolelos and N. Tagmatarchis, Chem. Commun., 2013, 49, 9128-9130.

15. B. Liu, H. Fang, X. Li, W. Cai, L. Bao, M. Rudolf, F. Plass, L. Fan, X. Lu and D. M. Guldi, Chem. - Eur. J., 2015, 21, 746-752.

16. J. L. Sessler and D. Seidel, Angew. Chem., Int. Ed., 2003, 42, 5134-5175.

17. M. E. El-Khouly, S. Fukuzumi and F. D'Souza, ChemPhysChem, 2014, 15, 30-47.

18. A. Loudet and K. Burgess, Chem. Rev., 2007, 107, 4891-4932.

19. F. Diederich and M. Gómez-López, Chem. Soc. Rev., 1999, 28, 263-277.

20. M. Ortiz, S. Cho, J. Niklas, S. Kim, O. G. Poluektov, W. Zhang, G. Rumbles and J. Park, J. Am. Chem. Soc., 2017, 139, 4286-4289.

21. M. C. Scharber, D. Mühlbacher, M. Koppe, P. Denk, C. Waldauf, A. J. Heeger and C. J. Brabec, Adv. Mater., 2006, 18, 789-794.

22. D. M. Guldi and M. Prato, Acc. Chem. Res., 2000, 33, 695-703.

23. N. Martín, Chem. Commun., 2006, 0, 2093-2104.

24. D. M. Guldi, B. M. Illescas, C. M. Atienza, M. Wielopolski and N. Martín, Chem. Soc. Rev., 2009, 38, 1587-1597.

25. A. J. Stasyuk, O. A. Stasyuk, S. Filippone, N. Martin, M. Solà and A. A. Voityuk, Chem. - Eur. J., 2018, 24, 13020-13025.

26. M. Izquierdo, B. Platzer, A. J. Stasyuk, O. A. Stasyuk, A. A. Voityuk, S. Cuesta, M. Solà, D. M. Guldi and N. Martín, Angew. Chem., Int. Ed., 2019, DOI: 10.1002/anie.201901863.

27. A. J. Stasyuk, O. A. Stasyuk, M. Solà and A. A. Voityuk, Chem. - Eur. J., 2019, 25, 2577-2585.

28. S. Bosi, T. Da Ros, G. Spalluto and M. Prato, Eur. J. Med. Chem., 2003, 38, 913-923.

29. C. M. Sayes, J. D. Fortner, W. Guo, D. Lyon, A. M. Boyd, K. D. Ausman, Y. J. Tao, B. Sitharaman, L. J. Wilson, J. B. Hughes, J. L. West and V. L. Colvin, Nano Lett., 2004, 4, 1881-1887.

30. J. L. Delgado, P.-A. Bouit, S. Filippone, M. Á. Herranz and N. Martín, Chem. Commun., 2010, 46, 4853-4865.

31. R. W. Wagner, T. E. Johnson and J. S. Lindsey, J. Am. Chem. Soc., 1996, 118, 11166-11180. 
32. D. T. Gryko, C. Clausen, K. M. Roth, N. Dontha, D. F. Bocian, W. G. Kuhr and J. S. Lindsey, J. Org. Chem., 2000, 65, 7345-7355.

33. D. Kuciauskas, P. A. Liddell, S. Lin, T. E. Johnson, S. J. Weghorn, J. S. Lindsey, A. L. Moore, T. A. Moore and D. Gust, J. Am. Chem. Soc., 1999, 121, 8604-8614.

34. H. Imahori, D. M. Guldi, K. Tamaki, Y. Yoshida, C. Luo, Y. Sakata and S. Fukuzumi, J. Am. Chem. Soc., 2001, 123, 6617-6628.

35. H. Imahori, Y. Sekiguchi, Y. Kashiwagi, T. Sato, Y. Araki, O. Ito, H. Yamada, S. Fukuzumi, Chem. Eur. J., 2004, 10, 3184-3196.

36. C. Stangel, F. Plass, A. Charisiadis, E. Giannoudis, G. Chararalambidis, K. Karikis, G. Rotas, G. E. Zervaki, N. N. Lathiotakis, N. Tagmatarchis, A. Kahnt and A. G. Coutsolelos, Phys. Chem. Chem. Phys., 2018, 20, 21269-21279.

37. Y. Xu, B. Wang, R. Kaur, M. B. Minameyer, M. Bothe, T. Drewello, D. M. Guldi and M. von Delius, Angew. Chem., Int. Ed., 2018, 130, 11723-11727.

38. A. Bagaki, H. B. Gobeze, G. Charalambidis, A. Charisiadis, C. Stangel, V. Nikolaou, A. Stergiou, N. Tagmatarchis, F. D'Souza and A. G. Coutsolelos, Inorg. Chem., 2017, 56, 10268-10280.

39. N. Zarrabi, C. O. Obondi, G. N. Lim, S. Seetharaman, B. G. Boe, F. D'Souza and P. K. Poddutoori, Nanoscale, 2018, 10, 20723-20739.

40. F. D'Souza and O. Ito, Chem. Commun., 2009, 0, 4913-4928.

41. C. Stangel, C. Schubert, S. Kuhri, G. Rotas, J. T. Margraf, E. Regulska, T. Clark, T. Torres, N. Tagmatarchis, A. G. Coutsolelos and D. M. Guldi, Nanoscale, 2015, 7, 2597-2608.

42. C. B. Kc and F. D'Souza, Coord. Chem. Rev., 2016, 322, 104-141.

43. A. N. Kursunlu, RSC Adv., 2014, 4, 47690-47696.

44. H. Imahori, Y. Mori and Y. Matano, J. Photochem. Photobiol., C, 2003, 4, 51-83.

45. C. B. Kc, G. N. Lim and F. D'Souza, Nanoscale, 2015, 7, 6813-6826.

46. A. N. Amin, M. E. El-Khouly, N. K. Subbaiyan, M. E. Zandler, M. Supur, S. Fukuzumi and F. D'Souza, J. Phys. Chem. A, 2011, 115, 9810-9819.

47. V. Bandi, F. P. D'Souza, H. B. Gobeze and F. D'Souza, Chem. - Eur. J., 2015, 21, 2669-2679.

48. V. Bandi, F. P. D'Souza, H. B. Gobeze and F. D'Souza, Chem. Commun., 2016, 52, 579-581.

49. J. Yang, F. J. Cai, X. M. Yuan, T. Meng, G. X. Xin, S. F. Wang, C. P. Gros and H. J. Xu, J. Porphyrins Phthalocyanines, 2018, 22, 777-783.

50. Y. Yan, F. Wu, J. W. Qin, H. J. Xu, M. H. Shi, J. F. Zhou, J. Mack, G. Fomo, T. Nyokong and Z. Shen, Rsc Adv., 2016, 6, 72852-72858.

51. C. Y. Lee, J. K. Jang, C. H. Kim, J. Jung, B. K. Park, J. Park, W. Choi, Y. K. Han, T. Joo and J. T. Park, Chem. - Eur. J., 2010, 16, 5586-5599.

52. Q. Huaulmé, A. Sutter, S. Fall, D. Jacquemin, P. Lévêque, P. Retailleau, G. Ulrich and N. Leclerc, J. Mater. Chem. C, 2018, 6, 9925-9931.

53. F. Dumur, N. Gautier, N. Gallego-Planas, Y. Şahin, E. Levillain, N. Mercier, P. Hudhomme, M. Masino, A. Girlando, V. Lloveras, J. Vidal-Gancedo, J. Veciana and C. Rovira, J. Org. Chem., 2004, 69, 2164-2177.

54. Z. Mahmood, K. Xu, B. Küçüköz, X. Cui, J. Zhao, Z. Wang, A. Karatay, H.G. Yaglioglu, M. Hayvali and A. Elmali, J. Org. Chem., 2015, 80, 3036-3049.

55. S. Kumar, K.G. Thorat, and M. Ravikanth, J. Org. Chem. 2017, 82, 6568-6577.

56. F. L. Hirshfeld, Theor. Chim. Acta, 1977, 44, 129-138.

57. S. Van Damme, P. Bultinck and S. Fias, J. Chem. Theory Comput., 2009, 5, 334-340.

58. R. A. Marcus and N. Sutin, Biochim. Biophys. Acta, Rev. Bioenerg., 1985, 811, 265-322.

59. J. Tomasi, B. Mennucci and R. Cammi, Chem. Rev., 2005, 105, 2999-3094.

60. A. D. Becke, Phys. Rev. A, 1988, 38, 3098-3100.

61. C. Lee, W. Yang and R. G. Parr, Phys. Rev. B, 1988, 37, 785-789. 
62. F. Weigend and R. Ahlrichs, Phys. Chem. Chem. Phys., 2005, 7, 3297-3305.

63. F. Weigend, Phys. Chem. Chem. Phys., 2006, 8, 1057-1065.

64. K. Eichkorn, O. Treutler, H. Öhm, M. Häser and R. Ahlrichs, Chem. Phys. Lett., 1995, 240, 283-290.

65. TURBOMOLE 7.0 2015, a development of the University of Karlsruhe and Forschungszentrum Karlsruhe GmbH 1989-2007, TURBOMOLE GmbH since 2007; available from http://www.turbomole.com.

66. S. Hirata and M. Head-Gordon, Chem. Phys. Lett., 1999, 314, 291-299.

67. T. Yanai, D. P. Tew and N. C. Handy, Chem. Phys. Lett., 2004, 393, 51-57.

68. M. J. Frisch, G. W. Trucks, H. B. Schlegel, G. E. Scuseria, M. A. Robb, J. R. Cheeseman, G. Scalmani, V. Barone, G. A. Petersson, H. Nakatsuji, X. Li, M. Caricato, A. V. Marenich, J. Bloino, B. G. Janesko, R. Gomperts, B. Mennucci, H. P. Hratchian, J. V. Ortiz, A. F. Izmaylov, J. L. Sonnenberg, Williams, F. Ding, F. Lipparini, F. Egidi, J. Goings, B. Peng, A. Petrone, T. Henderson, D. Ranasinghe, V. G. Zakrzewski, J. Gao, N. Rega, G. Zheng, W. Liang, M. Hada, M. Ehara, K. Toyota, R. Fukuda, J. Hasegawa, M. Ishida, T. Nakajima, Y. Honda, O. Kitao, H. Nakai, T. Vreven, K. Throssell, J. A. Montgomery Jr., J. E. Peralta, F. Ogliaro, M. J. Bearpark, J. J. Heyd, E. N. Brothers, K. N. Kudin, V. N. Staroverov, T. A. Keith, R. Kobayashi, J. Normand, K. Raghavachari, A. P. Rendell, J. C. Burant, S. S. Iyengar, J. Tomasi, M. Cossi, J. M. Millam, M. Klene, C. Adamo, R. Cammi, J. W. Ochterski, R. L. Martin, K. Morokuma, O. Farkas, J. B. Foresman and D. J. Fox, Gaussian, Inc., Wallingford CT, 2016.

69. S. Grimme, J. Antony, S. Ehrlich and H. Krieg, J. Chem. Phys., 2010, 132, 154104.

70. S. Grimme, S. Ehrlich and L. Goerigk, J. Comput. Chem., 2011, 32, 1456-1465.

71. A. Dreuw and M. Head-Gordon, Chem. Rev., 2005, 105, 4009-4037.

72. M. E. Casida and M. Huix-Rotllant, Annu. Rev. Phys. Chem., 2012, 63, 287-323.

73. A. Chantzis, A. D. Laurent, C. Adamo and D. Jacquemin, J. Chem. Theory Comput., 2013, 9, 45174525.

74. Zhurko G. A. Chemcraft 1.80 (build 523b) - graphical program for visualization of quantum chemistry computations. (https://chemcraftprog.com)

75. F. Plasser and H. Lischka, J. Chem. Theory Comput., 2012, 8, 2777-2789.

76. F. Plasser, S. A. Bäppler, M. Wormit and A. Dreuw, J. Chem. Phys., 2014, 141, 024107.

77. A. A. Voityuk and N. Rösch, J. Chem. Phys., 2002, 117, 5607-5616.

78. A. A. Voityuk, Phys. Chem. Chem. Phys., 2012, 14, 13789-13793. 